\title{
Analysis on Difficulties with the Effective Supply of Highway in China and Its Countermeasures
}

\author{
Min Tang \\ School of Public Policy and Administration \\ Xi'an Jiaotong University \\ Xi'an, China \\ E-mil: tangmim@ foxmail.com
}

\author{
Zehao Zhang \\ School of Public Policy and Administration \\ Xi'an Jiaotong University \\ Xi'an, China
}

\begin{abstract}
Highway free during the holidays" policies implemented by our government caused serious congestion problems. How to further improve the efficiency of the highway so that it can be scientifically used whatever free or not becomes a typical problem in effective supply of public goods. Firstly, public goods attribute of highway under different scenarios were discussed to explain the principles of highway toll, and the root causes of highway extension fees, charges exorbitant issues were analyzed. Use economics to analyze severe congestion reasons caused by highway free meanwhile referring advanced experience of developed countries and regions in supplying the highway and put forward suggestions to achieve effective supply of highway in our country.
\end{abstract}

Keywords—highway; public goods; supply

\section{INTRODUCTION}

Highway occupied an important position in China's transportation. While highway mileage in our country only accounts for about $2 \%$ of the total mileage of road network, it bears more than $20 \%$ of the car travelling amount. Especially since the implementation of "loan to build roads, fee to back loan" policy, highway construction get rid of state funding constraints, relying on its own rolling development formed a virtuous cycle of build ing mechanisms to promote the highway development by leaps and bounds. By the end of 2012, our highway mileage reached $96,000 \mathrm{~km}$, after the United States, ranking second in the world. However, the government - led, diversified investment, market-oriented operation system of highway ensures funds for construction and efficiency but brings new problems, such as the contradictions caused by different properties between highway quasi-public goods and profit -driven operations, along with the conflict caused by highway social benefits objectives and economic efficiency require ments. After recovering the loan, highway fee still exit; highway toll is relatively higher than other countries and regions. The existence of these problems, making public appeals for the return of highway's public goods attribute increasingly rising.

To alleviate the negative problems brought about highway construction and usage and return public welfare of highway to the public, a series of policies were introduced. July 24, 2012, the State Council issued "Notice on Endorsing the
Implementation Program of the Ministry of Transport and Other Departments to Waive the Small Passenger Car Toll in Major Holidays". August 3, 2012, the Ministry of Transport decided to begin the implementation of the "notice" requirement in National Holiday of 2012.Till September 23, 2012, more than 20 provinces, including Beijing, Shanghai, Shandong and so on implement highway free policy in the National Day ${ }^{[1]}$. Major holidays' highway free open policy which received enthusiastic response from all sectors of society, leading to a sharp increase in traffic in a short time, caused tremendous pressure on highway management and vehicle safety. Highway severe congestion and continued occurring accidents, not only affects the efficiency of the vehicle travel, but also discounts the effect of major holidays' highway free policy. Whether toll or free supply of highway have not solved the effective supply of China's highway which should adapt with the consumer demand and consumption ability.

Motorway public goods nature, but the construction and development of the highway is unique, relying solely on the government or the market supply cannot achieve effectiveness highway supply, the need to achieve by way of compensation for the use of its use value ${ }^{[2]}$.

Highway owns the nature of public goods, but the construction and development of the highway is unique. Rely ing solely on the government or the market supply cannot achieve effective highway supply, needing a paid use way to realize its value ${ }^{[2]}$. Over the years, there are three tendentious views on the effective supply of the highway: First, the necessity of highway toll. The purpose is to avoid the crowded occurring during the use of public goods. Englmann (1997) considered that when road congestion to a certain extent, charges will not reduce consumer surplus, but will increase social welfare ${ }^{[3]}$.Georgina et al. (1994) pointed out that the road toll will prevent traffic congestion ${ }^{[4]}$. Theoretical Foundation of highway toll is its quasi-public product attributes [5] Wang Guoqing et al. (2000) thought that enterprise management and market operation system is the solution to highway construction highway infrastructure demand and supply contradiction ${ }^{[6]}$.

Song Shengli (2006) pointed out that road infrastructure investment have a greater benefit of the national economy, as long as the generalized cost of such benefits outweigh toll road 
investment recovery mode generated, the toll road policy can be considered as effective ${ }^{[7]}$. Second, there is a variety of problems on highway toll. Increased transportation costs, heavy burden on loans interest, and prone to monopoly operators are all typical problems that exist in highway toll ${ }^{[8]}$. Wang Jianping (2006) argue that highway toll in China also arbitrary presents extend the fee period in will, unreasonable set of toll station and higher fee and other phenomena ${ }^{[9]}$. Third, proposed effective countermeasures on highway supply. Li Xiaoming (2005) emphasized the role of the State Investment and Regulation in the supply of the highway ${ }^{[10]}$; National Development and Reform Commission Macroeconomic Research Group (2010) pointed out that the key to an effective solution is to optimize the road toll highway financing structure reduce the high fees and deferred charges ${ }^{[11]}$. In addition, there are scholars defined the origins of highway crowding as imbalance on public products supply and demand ${ }^{[12]}$.

Academic research provides a theoretical reference and research platform for this article. However, since few studies consider the existing highway congestion impact on public product attributes, there are no conditions limiting highway toll, the proposed countermeasures difficult to effectively solve the existence plight on our supply of highway.

Taking the effective supply of highway as the research object, this paper respectively analyzed overdue fees and charges too high on highway and congestion caused by free charge, based on definition of highway's public goods attribute. By drawing on international experience, it proposes suggestions to achieve effective supply of highway.

\section{EASE OF USE PUbliC PROdUCt ATtRIBUTE OF HIGHWAY}

Public goods and private goods have different characteristics, namely, consumption of non-exclusive and non-competitive. In analyzing the product nature of the highway, this paper introduces two analytical parameters. First, competition discriminative parameter $\xi$. Marginal congestion costs determined by the number of services or products $\mathrm{Q}$, is also the reason for highway consumption competitive. When $\mathrm{Q}$ is greater than the minimum amount of congestion (i.e., the largest traffic highway can accommodate), $\xi=1$, there are competing; When $\mathrm{Q}$ is less than the minimum amount of congestion, $\xi=0$, there is no competition. The second parameter is the operating factor $\beta$, which is used to judge the exclusivity of highway. The operational coefficient highway is defined as the ratio of the value of market $\mathrm{V}$ and the highway construction costs $C, \beta=\mathrm{V} / \mathrm{C}$. When $\beta=0$, the highway is free and open, not exclusive; The higher the $\beta$, the greater the income, the exclusiveness of the highway is also stronger.

Taking $\xi, \beta$ as the evaluation criteria, the following judgments may be made on the highway's public good attributes:

1) $\xi=0, \beta=0$.In this case, expressway toll is 0 and the highway is no exclusive. With less traffic, there is no competition and the highway is pure public goods.

2) $\xi=1, \beta=0$. In this case, expressway toll is 0 and the highway is no exclusive;
However, this time the traffic is marginally heavier, a certain congestion costs existing.

3) $\xi=0, \beta<1$.Highway is not competitive. However, due to the need to charge a fee, this highway belongs to quasioperational natural monopoly products, vehicle on which does not produce congestion costs.

4) $\xi=1, \beta<1$.Highway is a quasi-operating public goods with not strong exclusivity. With more vehicles, there is a certain degree of congestion costs.

5) $\xi=0, \beta \geq 1$.There is no competition of the highway. But with high exclusivity, it pertained to profit-making natural monopoly products.

6) $\xi=1, \beta \geq 1$.Owing to both of highly competitive and exclusivity, the highway is a typical private goods.

For 1), 2) types of highway, the market will be difficult to achieve effective supply of investment and the government can only regard them as costly welfare investment; For 3) ,4) types of highway, operating coefficient is less than 1 , indicating that the toll highway pricing process less than the cost, needing for government investment. For 5), 6) types of highway, whose toll is greater than the cost, can be supplied through market mechanisms. But because the government has strictly controlled expressway toll, and the market competition will lead to decline in the level of charges, 5), 6) types of highway does not exist in our country.

Based on competitive parameters $\xi$ and operating parameters $\beta$, the following conclusions can be drawn: First, when the highway toll, $\beta<1$, the highway is a certain exclusiveness of quasi-public goods. Once the traffic is too crowded, it also has some competition. Second, when the highway is free, $\beta=0$, the highway does not exclusive. If traffic is small, $\xi=0$, the highway is not competitive, and is pure public goods; If traffic more than the minimu m amount of highway congestion, $\xi=1$, due to the presence of congestion cost of leaving the highway, competition between the vehicles would leading the highway transformed to quasi public good.

\section{ANALYSIS OF HIGHWAY TOLL SUPPLY FAILURE}

\section{A. Loss of Efficiency Caused by HighwayToll}

To set the level of highway toll is a complex process, it is related to motorways supply and demand, the economic benefits of the highway suppliers and consumer, and social welfare. In particular operating highway, with the conditions of natural monopolies, once its toll level determined by market mechanisms will inevitably lead to a certain loss of efficiency. 


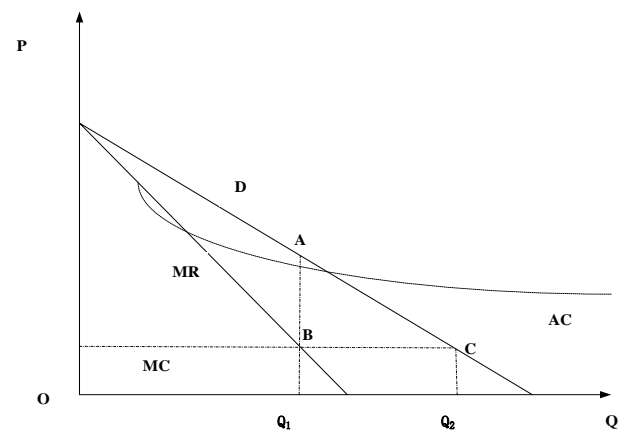

Fig. 1. highway efficiency losses caused by nat ural monopolies

As is shown in "Fig. 1", the vertical axis represents the level of highway toll $\mathrm{P}$, the horizontal axis represents supply quantity highway Q. Because of the highway's natural monopoly, its supply costs diminished with volume growth, with an average cost curve AC tilt to the right. As the demand curve D of quasi-public good highway laid on the right side of the marginal revenue curve MR, MC marg inal cost curve is a straight line parallel to the horizontal axis of inelastic. Supply amount Q2 which are determined by the intersection of marginal curve MC and demand curve D conform to the principle of social welfare maximization.

However, under the market mechanism, the monopolist will fix the supply amount at point $\mathrm{B}$ which is the intersection of marginal cost curve $\mathrm{MC}$ and marginal revenue curve $\mathrm{MR}$, then supply amount of highway shrink to Q1. At this time, if consumers want to get the supply of $\mathrm{Q} 2$, price rising is the only way, which leads to areas of efficiency loss $\triangle \mathrm{ABC}$.

\section{B. Rent-seeking BehaviorCaused by Highway Toll}

When the industry with natural monopoly characteristics cannot be effectively supplied under the premise of market competition mechanism, should improve supply efficiency by government intervention. Controlling the level of highway toll is an economic regulatory policy of the government whose purpose is to make the highways tend to be Pareto optimal allocation of resources. However, in the process of highway toll, the level of charges related financial information is not public, leading to the information asymmetry between providers and consumers. There are some defects on highway investment and financing system and shortcomings on the fairness of supply of highway. In particular, some highway related departments pursue self-interest and regard partial profit maximization as an administrative goal, which led to departments or individuals rent, rent-setting behavior.

According to public choice theory, highway "rent-seeking and rent-setting" relationship stems from government intervention in the highway market [15]. Government intervention is not necessarily leading to rent-seeking activities, but will create the conditions for the rent-seeking activities [16].Rent-seeking and rent-setting behavior brings efficiency loss in the following areas: Measures taken by rent-seekers such as spending time, effort and money to lobby or smooth the relationship enhanced their efficiency but reduced social efficiency. Rent-seeking activities will lead to the struggle for power between government departments and officials, impede the implementation of public decision-making, lowering administrative efficiency. Rent-seeking and rent-setting behavior in highway makes surcharge amount includes not only the social marginal cost, marginal costs associated individuals, but also rent-seeking, rent-setting cost, and finally lead to the level of the highway toll rises or postponed indefinitely charges.

\section{FAILURE ANALYSIS ON CAUSES OF CONGE STION WHEN HIGHWAY FREE}

\section{A. Insufficient Production Brought by Highway Free}

Supply efficiency of highway free performed in whether the Government provided sufficient free highways, the number provided is able to meet the needs ofconsumers.

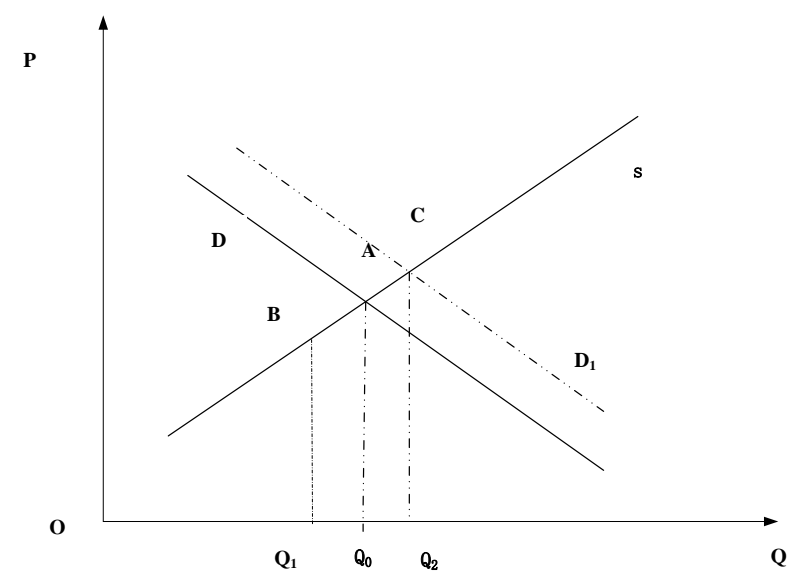

Fig. 2. Supply efficiency on highway

As shown in "Fig. 2", the horizontal axis represents the level of charges highway, while the vertical axis represents the demand scale of consumers. Curve D represents the demand curve freeway, and curve $S$ represents the supply curve of highway, both under equilibriu m conditions intersect at point $A$. Demand Q0 which corresponds to point A is capable of scale supplied by government and yields accepted by users.

In fact, the freeway is limited. Once its equilibrium quantity cannot achieve Q0, the supply amount of the supply curve $\mathrm{S}$ is decreased to point B corresponding to a yield of Q1. However, the birth of free highways will change consumer demand. The demand curve changes into a line D1 which parallels to and above the curve $\mathrm{D}$, and intersect with the supply curve $\mathrm{S}$ at $\mathrm{C}$, corres ponding to the demand amount of Q2.Obviously, there is a difference value Q2-Q1between demand and supply amount of consumer, which is insufficient production irreparable. Nevertheless, consumers will not give up consumption because of lack of supply; on the contrary, precisely because of the nonexclusive brought by the free highway, consumers have crowded into the same road, causing serious congestion.

\section{B. Excessive Consumption Caused by Free Supply}

When provided free of charge, highway changed into a non-exclusive, non-competitive and scarcity pure public goods. 
Scarcity public goods prone to birth "free rider" phenomenon, the result of which is to bring the actual consumption of public goods exceeding expected consumption, namely the excessive consumption. Excessive consumption increased to a certain extent, is overcrowding.

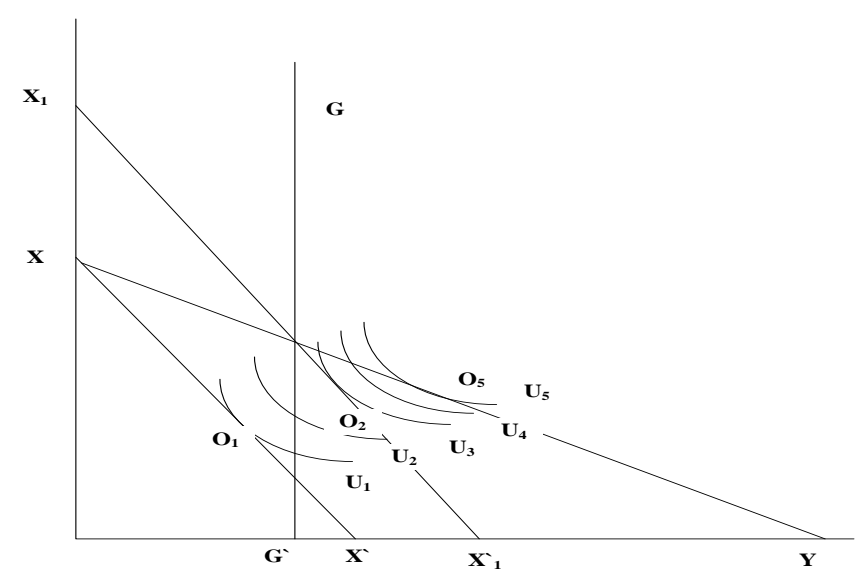

Fig. 3. Excessive consumption of free highway supply

Assume car travelers are all rational "economic man". In the process of how to choose consumption, they will always keep the cost under budget line constraint, with minimal cost to get the maximu m benefits.

In "Fig. 3", the horizontal axis represents the number of traveling vehicles and the vertical axis represents the utility of those who travel by car; XX'is the budget line of car travel during highway toll period, while GG' represents the supply of the highway. At this time, the maximum utility of car travelers can reach U1 and utility curve U1 and the budget line tangent to point $\mathrm{O} 1$, meaning that car travelers' highway demand less than the supply of the highway.

During the highway free, due to relative changes in price, the slope of the budget line changed and the budget line XX 'move to XY. When the highway supply is adequate, indifference curve U5 of car travelers tangent to the new budget line XY at point Q5, namely those who travel by car achieve maximize utility at point Q5 .However, the supply of highways is limited, still keeping in GG' and point Q5 does not really appear. But under the motive action of pursuing point Q5, demand of car travelers is greater than the supply of the highway, causing road congestion and traffic accidents. As a result, under the conditions of highway free, the difference between amount of the demand and the supply of highway for car travelers is Y-G'. Due to road congestion and traffic accidents, total utility consumers actually received are less than the maximum utility $\mathrm{U} 1$ that can be achieved under the conditions of charge.

\section{Free Riding Caused by Highway Free}

Hitchhiking refers to a kind of speculation which refers to not pay the cost and reap the benefit of others. Non-exclusive and non-competitive of public goods provides space for hitchhiking. Free-riding behavior lead to "tragedy of the commons": People will maximize the use of public resources and at the expense of the public interest.

Motorway free provides the conditions to the birth of freeriding behavior, which led to highway traffic volume breaks the minimu mamount of traffic congestion.

For ease of analysis, consumers can choose to set the freeway, free mileage, A-type and B-type consumer the number of consumers .

Set $A$ as a collection of freeway which can be chose by consumer, when there is only toll highway, $A=\{C\}$; when part of highway is free, $A=\{c, f\}$.The highway mileage is $\mathrm{L}$, in which free mileage is $m$ and highway saturation (noncongested highest) bearing number is $N$. And then set that there are two types of highway consumer, A-type and B-type. Sum of A-type and B-type consumer is $U$. Among them, as long as the level of charges highway within their psychological expectations, A-type consumers will make use decisions, while for B-type consumers, only in addition to the level of charges, quality service, congestion and convenience of the highway must be fully understand, can they be transformed into A-type consumers.

When all highways is toll, the maximum carrying capacity $G(0)=N / L$ is the smallest congested capacity of highway. Proportion of A-type consumers is $P=P\left(S_{c}\right)_{; \text {while }} P^{\prime}\left(S_{c}\right) \geq 0,0<P(0) \leq 1$, in which $S_{c}$ belongs to $\left[0, S_{\max }\right]$ and $P\left(S_{\max }\right)=1$.If there is no free highway, $S_{c}=S_{\max }$ and the proportion of A-type consumers reached $100 \%$.In this case, the number of consumers who use toll highways is $U P\left(S_{c}\right)$ and road carrying capacity is $G(P) \leq N / L$, so no congestion occurs. However, once $G(P) \geq N / L$, even if there will be a fee highway, congestion occur. Here frequent congestion problems after free highway are mainly analyzed.

As part of highway free, hitchhiking phenomenon appears and consumers began to flow to free motorway. $\delta$ represents the proportion of consumers dispersed to free highway, $\delta=\delta(\beta)$,in which $\beta(\beta \leq 1)$ is the freebie factor, reflecting the highway free rider effect. The greater the $\beta$, the more users dispersed to free highway. At this time, the influx number of consumers to free freeway is $\delta(\beta) U P\left(S_{c}\right)$ and capacity of free highway is $G(F)=\delta(\beta) U P\left(S_{c}\right) / m$.

Since China adopted the "all national toll roads free for small passenger cars" policy, it can be considered $L=m$. If $\delta(\beta) U P\left(S_{c}\right) \geq N, G(F) \geq G(0)$, congestion is evitable, while if $\delta(\beta) U P\left(S_{c}\right) \leq N$, congestion will not occur. Whether congestion depends on how many consumers use the free highway. Under hitchhiking psychological, the possibility of 
maximizing the benefits for the individual and transformed into A-type consumer greatly increased as the consumers are rational economic man. They flocked to free the highway in successive, resulting in the number of road carries far beyond, causing serious congestion problems.

Hitchhiking is not real needs of people. The source of this non-real needs origins from people's possession of money and resources. If a person acquires the "free rider" in public goods consumption, he will save more money and resources to increase private consumption of private goods, so as to achieve their maximum satisfaction. In free highway use, for free use of resources and the psychology of possession occupation, individuals are reluctant to give up the use of public resources for such free-riding opportunities, so that they have flocked to the freeway, causing highway congestion, leading to unachievable Pareto optimal state.

\section{SUGGESTIONS ON EFFECTIVE SUPPLY OF FREE HIGHWAY}

\section{A. Setting Scientific Restriction for Free Highway Passage}

Relieving congestion caused by highway should take maximizing the net benefit of all users as the goal. Firstly, at the institutional level, allowing various regions decide free time discretionarily and the Ministry of Transport only need to develop regulatory guidance. Parts of the country in accordance with the guidance of the Ministry of Transport, according to the prevailing situation in the region highway, adjust free highway sections and period in order to coordinate the traffic volume of highways and roads. Secondly, the highway should be free to motor buses which carry more passengers. In terms of this no matter from the point of reducing congestion, increasing transportation efficiency, energy reduction, or so that majority of low-income, non-drive travelers can enjoy equitable services, can social welfare increase. Lastly, in concession operating agreement and highway toll transfer agreement between government and enterprises, the expansion of the range of the vehicle to be free should be increased. Furthermore, it should encourage local governments or companies through buyouts certain highway right-of-way, to achieve a certain toll highway free access.

\section{B. Improving Highway Free Time Management System}

Highway management and the government should establish a sound highway free period management system, including : 1)Establishing intelligent traffic management systems to monitor highway traffic situations and timely issue traffic information, so as to reduce highway congestion occurrence.2) Founding highway emergency management headquarters, the aim of which is to discover chaotic traffic signs and issue a directive immediately, and deploy police timely to dispose, be responsible for management and control.3) To strengthen the management of large trucks in free period. Opening a special channel for large trucks to avoid causing access barriers when meet small and medium vehicle.

\section{Attracting Private Capital Investment in Highway Construction Operation}

Through privatization, investment and ownership can be clearly and the enthusiasm of investors is fully mobilized.
Through internal balances, the privatization of the blind pursuit of profit and harm the interest of consumers can be prevented. It should be that: 1) To develop policies and regulations in infrastructure construction as soon as possible to attract private capital. Addressing the incomplete prevailing policy to ensure that private investment are deem as equal with other forms of ownership, effectively enjoying national treatment. 2) In order to attract private capital to invest in the road construction project, road projects (such as the western highway construction) which have an important role in the economic development should be given the right profit margins. The government can take tax-free, a gift of land and financial subsidies other ways to enhance investors' willingness to participate. 3) Flexibly use various financing methods to attract private capital at all levels to enter the field of road construction. Private enterprises enter the field of road construction will mainly take the joint, joint venture, funds, shares, etc., but does not rule out stronger individual-owned private enterprises to enter the sole proprietor.

\section{Establishment of Expressway Development Fund and Cancellation Fee Policy}

According to practical experience of foreign transport development, the use of legislation to establish a system of earmarked funds for the construction of transportation facilities can ensure a stable source of funding. Specific financial resources of traffic infrastructure construction main ly refer to a special fund, which constitute of the refined oil consumption tax, vehicle purchase tax. Given China's highway construction, maintenance and updating tasks is much heavier, especially in the western region, it is impossible to fully use tolls to repay investment in road projects. The appropriate part of the general budget revenues finance and private investment attracted can be made to establish highway development fund, used in highway construction, maintenance and updating. In the early construction of fund, the collection of some highway user fees are reasonable, but with the improvement in tax policy and the stock market on behalf of the charges, highway user fees should be gradually reduced, and ultimately achieve zero toll motorway.

\section{REFERENCES}

[1] The Central People's Government of People's Republic of China, more than 20 provinces in the introduction of the National Day, Mid-Autumn Festival highway free details. [EB/OL].[2012-09-24]. http://www.gov.cn/jrzg/2012-09/24/ content_2231568.html 2012.

[2] Martin W.I. Proving efficiency and equity in transportation finance [M].Washingt on D C : The Brooking Institution , 2003.

[3] F. Englmann Ray.Theoretical explorations in economic growth and transport at ion [D]. Boston University,1997,(3):19-25

[4] Georgina Santos, Simon P Shepherd, Road pricing theory, empirical assessment and policy[M]. Kluwer academic publisher,1994,(11):56-64.

[5] Li Chongen. Road Traffic Revenue Economics [M] Beijing: China Communications Press, 2003.

[6] Wang Guoqing, Bing-gang of Industrial Property and the industrialization of China expressway highway $[\mathrm{J}]$ Xi'an Jiaotong University, 2000, (4): 64-67

[7] Song Shengli. Rational View of the Turnpike [J] Chinese highways, 2006, (20): 25-28.

[8] Huang Yongsheng, Xu Yifeng. Toll Road Problems and Count ermeasures [J] Traffic Management, 2006, (3): 20-21 
[9] Wang Jianping. Toll Road Construction Boom in the Cold Thinking [J] Chinese highways. 2006, (16): 67-73.

[10] Li Xiaoming. Reflections and Recommendations on China's highway toll policy [J] integrated transport, 2005, (1): 12-14.

[11] National Development and Reform Commission Task Force Institute of Macroeconomic 2009--2010 China's Macroeconomic Analysis and Forecast [M] Beijing: China Economic Publishing House, 2010

[12] Garrett Hardin. The Tragedy of the Commons [J]. Science,1968,(162):1243-1248. 